an exposition of his own theory, which is derived from the latter. The craters are now identified as collapsed volcanic calderas, the result of the collapse of the surface layers after the magma beneath them had been spewed out in a volcanic eruption. The book is divided into three parts of which the first outlines what is known about the Moon. The second examines the inadequacies of the meteoric theory and puts forward the 'caldera' theory. The third is concerned with reducing our present knowledge of the Moon's surface to a coherent system; it is largely devoted to an examination of the analogies between the surfaces of the Moon and Earth. The chief criticism to be levelled at this clear and closely reasoned book is the reckless use of the word 'random'. In a scientific work this word should be confined to its statistical sense.

In 1960 a team of workers led by G. P. Kuiper published their Photographic Lunar Atlas. This covered every part of the Moon's surface four times, at differing angles of illumination, on a scale of one millimetre to every $1.37 \mathrm{~km}$. on the Moon. The group have now published the first of a series of supplements. Twenty-nine of the best prints in the Atlas have been chosen to give a single coverage of the central portion of the Moon's disk. These are over-printed with a grid showing the orthographic $\xi, \eta$ co-ordinates, in other words, rectangular coordinates fixed in the Moon with $\xi$ axis northwards and $\zeta$ axis towards the Earth. The side of each square is 0.01 of the Moon's radius and positions can easily be read to an accuracy of 0.001 . There are two editions : $(A)$, on paper as described above and $(B)$, on 'Tensalex' plastic, with an additional grid showing selenocentric longitude and latitude at $2^{\circ}$ intervals.

D. H. P. Jones

\section{ISSUES IN EVOLUTION}

\section{Evolution after Darwin}

Edited by Sol Tax and Charles Callender. Vol. 3 : Issues in Evolution. Pp. viii +310 . (Chicago : University of Chicago Press; London: Cambridge University Press, 1960.) 60s. net.

THIS is the third volume of the Darwinian Centennial Symposium held at Chicago in 1959 (see Nature, 189, 340; 1961 for review of previous volumes). It comprises a first section on "Evolution and Religion" presented as essays on "Creation and Evolution in the Far East" by Ilza Veith, "Current Roman Catholic Thought on Evolution" by J. Franklin Ewing, S. J., and "Creation and Causality in the History of Christian Thought" by Jaroslav Pelikan (it is refreshing to note that a Roman Catholic view has been included). The second section is given over to the centennial celebrations, made up chiefly of a television preview panel of five scientists and including Adlai Stevenson, five panels on the origin of life, the evolution of life, man as an organism, the evolution of mind, and social and cultural evolution, with a variety of chairmen and panellists. There is a convocation address by Sir Julian Huxley, a final television postscript panel and a personal conclusion by the general editor, Sol Tax. The index to the three volumes is included in this third volume, and there are also lists and photographs of the participants and panels.

The five panels were essentially a form of glorified 'brains trust' on a high level, and they were all given in public to audiences of about a thousand people. Members of the panels for the most part were generally those who had previously given papers in the first two volumes of this series. Thus the opportunity was given to tie up loose ends, to give the participants a chance to air their agreements and disagreements, and to put forward their ideas. These panels were most interesting, and probably their chief result will be to enable readers of the whole series of essays to sort out facts from speculations and to assess the present state of evolutionary ideas.

It is perhaps significant that the three essays on "Evolution and Religion" together amounted to only 40 pages, less than half the number of pages of some of the essays on specialized topics in the first two volumes. About 90 pages were given to such subjects as the "Origin of Life"-a subject which surely by any serious standard is about 99 per cent speculation and fancy and only 1 per cent fact. The contrast here is illuminating, but, dare I say it without fear of excommunication by my fellow biologists, it also pinpoints the paucity of evolutionary theory as a whole in spite of the brilliant expositions of its magnificent edifice by so many scientists ; it also shows the weakness and barrenness of a purely materialistic concept of evolution and indicates without doubt that modern evolutionary theory has only a limited application to human beings. Why must biologists shut their eyes to the spiritual in man, pretend it is not there and thus remain only on the fringes of the study of the nature of man, who is demonstrably infinitely more than a mere animal ? It is a tragedy that a wonderful chance to produce a modern synthesis of knowledge of man and evolution has been missed in this great and superbly produced series of books born of a great idea by Sol Tax. But still the three books as a whole stand as probably the best of their kind so far published, and the committee under Sol Tax, the contributors and the University of Chicago, which made it possible, are to be congratulated and thanked.

P. G. Fothergint

\section{HETEROCYCLIC CHEMISTRY}

Pyridine and Its Derivatives

Edited by Erwin Klingsberg. (The Chemistry of Heterocyclic Compounds: a Series of Monographs, Vol. 14). Part 1. Pp. $\mathrm{x}+613$. 367s. Part 2 . Pp. $\mathrm{x}+576$. 282s. (New York: Interscience Publishers, Inc.; London : Interscience Publishers, Ltd., 1960 and 1961.)

\section{Heterocyclic Systems with Bridgehead Nitrogen Atoms}

Part 1. By William L. Mosby. (The Chemistry of Heterocyclic Compounds: a Series of Monographs, Vol. 15). Pp. viii + 747. (New York: Interscience Publishers, Inc.; London: Interscience Publishers, Ltd., 1961.) 360s.

$\mathrm{W}$ ITH two or three exceptions, previous volumes in the Interscience Series, The Chemistry of Heterocyclic Compounds, have tended to dwell on the less common heterocyclic systems. This is true of only one of the three volumes under review, and it is interesting to see the treatment accorded to a more familiar topic-Pyridine and its Derivatives. The first two volumes discussed here constitute Parts 1 and 2 of a four-volume treatise, which will surely 